\title{
Social Dynamics of Early Stage Co-Design in Developing Regions
}

\author{
Divya Ramachandran*, Matthew Kam*, Jane Chiu ${ }^{\dagger}$, John Canny ${ }^{*}$, James L. Frankel \\ *Berkeley Institute of Design and \\ Computer Science Division \\ University of California, Berkeley \\ \{divya,mattkam,jfc\}@cs.berkeley.edu
${ }^{\dagger}$ Google Inc. - Santa Monica ${ }^{1}{ }^{\#}$ Frankel and Associates, Inc. ${ }^{2}$
604 Arizona Ave
Santa Monica, CA
jane.chiu@gmail.com

\begin{abstract}
Technology arguably has the potential to play a key role in improving the lives of people in developing regions. However, these communities are not well understood and designers must thoroughly investigate possibilities for technological innovations in these contexts. We describe findings from two field studies in India and one in Uganda where we explore technological solutions in the domains of communication, microfinance and education. Two common underlying themes emerge from these studies: (1) local stakeholders can contribute cultural information relevant to design such as needs and practices through interaction with technology artifacts and (2) unique social network structures embedded within communities are crucial to the acceptance and potential adoption of technology. We end with a synthesis of the three experiences that draws some practical lessons for ICT designers to elicit meaningful feedback and participation from local stakeholders in developing regions communities.
\end{abstract}

Author Keywords

Digital divide, ICT4D, developing regions.

\section{ACM Classification Keywords}

H.5.m. Information interfaces and presentation (e.g., $\mathrm{HCI}$ ): Miscellaneous.

K.4.2. Computers and Society: Social Issues.

\section{INTRODUCTION}

The information revolution has arguably improved our quality of life by changing the way that we live, work and play. This revolution, however, has mostly taken place in the developed world. Brewer et al. argue that existing Information and Communication Technologies (ICTs) cater primarily to the First World and propose a research agenda that aims to extend this revolution to the developing world [2]. Since the needs and conditions of developing regions have been relatively less explored for the purpose of technology design, designers can benefit from lessons from

Permission to make digital or hard copies of all or part of this work for personal or classroom use is granted without fee provided that copies are not made or distributed for profit or commercial advantage and that copies bear this notice and the full citation on the first page. To copy otherwise, or republish, to post on servers or to redistribute to lists, requires prior specific permission and/or a fee.

CHI 2007, April 28-May 3, 2007, San Jose, California, USA.

Copyright 2007 ACM 978-1-59593-593-9/07/0004_..\$5.00. field experience to help them investigate the potential for designing and introducing ICT solutions in these contexts.

In this paper, we describe three field studies in three different developing regions which investigate how ICTs can promote: (1) personal communication for villagers in Tamil Nadu (TN), India, (2) micro-loans for low-income entrepreneurs in Uganda who lack collateral, and (3) universal primary education for school children from the rural schools and urban slums of Uttar Pradesh (UP), India. Though we conducted each of these studies separately, common themes emerged, namely (1) the importance of technology artifacts for attracting participants and eliciting design ideas and (2) the unique social dynamics that play a significant role for technology acceptance and potential adoption. Our main contribution is a discussion of these themes that generalizes some practical lessons on how ICT designers targeting developing regions can engage local stakeholders in early stage co-design.

We use the term early stage co-design to refer to the steps through which designers understand current tasks, needs and practices of potential users usually through processes like needs assessment, task analysis, contextual inquiry, or other methods that fall under the umbrella of formative design and evaluation in HCI. A common factor in our approach in all three studies was that we introduced technology artifacts to local stakeholders in the above communities - all of whom had very little exposure to technology - in order to observe their interactions with, and anchor our conversations in technology. However, here we are interested in the information we gathered that could contribute more generally to new technology designs, and not on specific feedback regarding the artifacts themselves. In focusing on the contextual and cultural information gathered from local stakeholders, it becomes clear that social networks play a dominant role in influencing the adoption and use of ICTs. This finding is consistent with prior studies on the diffusion of innovations into a society [22].

In our studies in $\mathrm{TN}$ and Uganda, we observed and interviewed stakeholders on how they interacted with semi-

\footnotetext{
${ }^{1}$ Participated in this work as a graduate student at University of California, Los Angeles.

2 Participated in this work as a consulting scientist at Mitsubishi Electric Research Labs.
} 
functional prototypes of a voicemail and point-of-sales handheld device respectively, so as to elicit feedback for new design directions. In UP, we loaned low-cost digital cameras to school children, so that they could take and share photographs of their everyday lives with us. By providing stakeholders with opportunities to interact with technology artifacts, we created occasions where they could reflect on and contribute their local knowledge to the design process. These artifacts were tools that we used together with conventional research methods in the social sciences, such as field observations and contextual [1], qualitative and survey interviews, to uncover cultural information about the communities.

Based on the two underlying themes mentioned previously, we end with five main lessons to aid designers in gaining insight from local stakeholders about how technology can fit into their context. These include lessons for (1) understanding the users' technology baseline and expectations, (2) designing tasks to elicit response, (3) opening up the study as a community event to draw in participants, (4) understanding the effects of peer learning and (5) creating opportunities to observe social networks at different levels. The relevant results from each of the studies that we present contribute to these lessons.

The next section gives a brief background and motivation for using technology in developing countries, followed by a discussion on related work. We then describe the three field studies in TN, Uganda and UP and present relevant results from each case. Drawing from these studies, we conclude by presenting lessons for effective early stage codesign in developing regions.

\section{BACKGROUND}

Global production has grown fifty-fold over the last two centuries. But the gap between the world's richest and poorest economies has also expanded dramatically from 4:1 in 1820 to 20:1 by 1998 [14], leaving the poor poorer. In The End of Poverty, noted economist Jeffrey Sachs attributes both phenomena to the fact that innovations offer productivity gains only to societies that are positioned to take advantage of these breakthroughs [23]. He explains that while science has propelled the industrial revolution, the poor have not historically benefited as much from technological advances because the global scientific research agenda is aligned with market forces which tend to neglect the poor. Along the same line, on top of arguing the need to research ICTs that address the local needs of developing regions, Brewer et al. highlight the benefits in healthcare, education, government, economic efficiency and disaster management that ICT deployments in developing regions contexts are beginning to demonstrate [2].

C.K. Prahalad [21] develops this argument further. He cites 12 case studies that illustrate how firms have reaped profits by serving consumers who live on $\$ 2$ or less per day through a combination of high-technology solutions and private, market-based enterprise. He argues that firms have to engage these underserved consumers actively and view them as joint problem-solvers, so as to co-create unique solutions, because existing products and services cannot adequately meet their needs. Prahalad also points out that designing appropriate technology solutions for this market will entail challenges, including the need to:

- Identify needs that may not be obvious to the designer or consumer participating in the design process. In particular, the consumer may not know how unfamiliar technology can benefit him or her

- Educate potential consumers (i.e. those who were not involved in the design process) about the benefits and usage of (relatively) novel technology solutions

- Account for the poor quality of local infrastructure and environment, such as fluctuating electricity, unreliable telecommunications, semi-literacy, low skill levels, noise, dust and the lack of sanitation

- Ensure affordability by taking low and fluctuating income streams as well as cash flows into account

These challenges emphasize the need to gather and utilize local knowledge during all stages of the design and deployment process - to co-design and co-deploy with the community [2].

Our choices of Uganda and India for fieldwork destinations are supported by the World Bank's statistics, which estimate that as of 2001, out of the 2.7 billion people worldwide that live on less than US \$2 per day, $89 \%$ of them are concentrated in sub-Saharan Africa, South Asia and East Asia [4]. In the next section, we begin by framing our work in the context of methods used in the early stages of the design process.

\section{RELATED WORK}

Contextual design is a popular method for assessing how new systems can be designed to suit users' tasks [1]. In this method, the term artifact refers to objects in the user's settings that serve as discussion props for users to relate current tasks centered on them. Here, however, we refer to technological items that we introduce to users as artifacts. Although these artifacts are not objects from the user's own context, they are still used similarly in discussions as tools for users to project (rather than relate) usage scenarios.

Rapid ethnography attempts to fill the gap between short design cycles and the long, complex nature of ethnographic research [16]. We echo guidelines used for rapid ethnography such as the use of key informants to get an insider's perspective of the user's context, but extend this to observing social interactions in community settings. We also focus on the use of technology to draw crowds and encourage interactions.

Cultural probes are thought-provoking artifacts which participants use to capture personal information to share with designers (like cameras) [7,8]. Technology probes are self-logging, strategically incomplete prototypes installed in 
real contexts to collect information about usage patterns, usability issues and the adoption process in order to inform new designs [11]. Our artifacts are used similarly to elicit feedback for new designs within the context of use, but are tools around which observations and interviews are conducted, rather than probes "sent out" to provoke sensitive and personal information over a long term.

Some members of the HCI community have explored iterative design of systems in the areas of microfinance and domestic labor in developing regions, in which they conducted focus groups and interviews to inform their designs $[15,17,18]$. However, these papers focus more on the systems themselves, rather than the social aspects around the design process as we do. Similarly others have looked at the design of novel interfaces in the areas of agriculture and education in developing regions [19,20].

There are many initiatives for building low-cost custom hardware for users in developing regions (listed in [13]), not to mention numerous grassroots level projects using technology for healthcare, agriculture, education, communication etc. However, there is limited documented work which focuses on early stages of co-design.

In the rest of this paper, we describe how we used technology artifacts in three different contexts to elicit response from users, and in the process observed social dynamics critical to the acceptance of technology within the community.

\section{FIELD STUDY \#1: PERSONAL COMMUNICATION IN TAMIL NADU, INDIA}

As Iqbal Quadir, the founder of GrameenPhone, a successful telecommunications venture for rural Bangladesh stated, "Connectivity is productivity" [9]. Quadir made this statement as he recalled a day in his childhood in Bangladesh on which he traveled eight miles by foot to purchase medicine from a pharmacy only to find that it was closed. Such stories are only too common in rural villages where travel by foot is the only means of access to information and services. As has been demonstrated widely in the First World, affordable personal communication is a key enabler for efficient coordination of activities ranging from daily routines to business dealings.

However, continuous power and connectivity are not affordable or reliable in developing regions [2]. Thus we focus on supporting asynchronous communication, for which intermittent connectivity can still provide a feasible infrastructure. The most common form of asynchronous communication in the First World is email; however, even if full local-language support for email could be made available, the serious issue of illiteracy renders such a solution impossible. Mitsubishi Electric Research Labs (MERL) has designed the Combadge [6] a mobile, asynchronous, voice-messaging device that supports intermittent connectivity, and uses a completely speechbased interface that could potentially transcend the illiteracy issue.
To understand existing modes of and needs for communication, we spent six days in Pudupalayam, an agricultural village outside the city of Erode in western Tamil Nadu (TN). The community in Pudupalayam like most typical agricultural villages in $\mathrm{TN}$ consists of relatively wealthy landowners, brokers who sell the crops to markets for a fair profit, and daily wage field workers. The field workers make up approximately half of the village population. In addition, there are also micro-entrepreneurs and their employees who engage in small retail businesses to meet common needs of the villagers.

\section{System Description}

The Combadge is a handheld, battery-powered device with a fully functional English interface. Its operation is solely controlled through a speech-based interface driven by a speaker-independent recognition engine. Each device also has an individualized address book driven by a speakerdependent recognizer which maps personalized nametags onto the GSM/GPRS SIM ID address or MAC address of a destination device. The Combadge is designed to work with different networking infrastructures through its built-in GSM/GPRS modem and compact flash slot to support a CF card for $\mathrm{WiFi}$, Ethernet, etc. It uses store-and-forward technology for its messages, and so does not require "always on" connectivity and is fully functional while offline. Each device has built-in microphones, a speaker and two push-to-talk buttons. Two lights flash to indicate the number of unsent and new messages.

We used the Combadge as an artifact to elicit feedback about existing and possible communication means. We adapted the interface to the local language, Tamil, by changing all of the output prompts spoken by the device. We decided to use the Wizard-of-Oz method to "fake" our Tamil recognition capability, since this would not detract from our priority of obtaining early-stage feedback from study participants.

\section{Methodology}

We conducted 37 sessions in uncontrolled settings at the village over four days. Each session typically consisted of between 1-7 participants (although in one case we had 14), and between 2-4 researchers and interpreters. The session lasted anywhere from 10 minutes to 1.5 hours, depending on the enthusiasm of the participants. These sessions were conducted in three different locations for reasons described later. Participants were initially recruited with the assistance of our host family, a prominent family in the village who spread the news about this study prior to our arrival. Sixty-four respondents participated in total.

Between 2-4 Combadge devices were used in each session, depending on the number of participants present. The Combadge address books were configured with personalized nametags mapped onto each of the other devices so that a participant could use one device to send voice messages to another. We ran a server on a laptop in 
ad-hoc mode to create a wireless network through which the devices could communicate.

Participants were first guided through the steps for sending a voice message to the other device being operated by an interpreter sitting beside them. Upon receiving the message, the interpreter would respond with a voice message, which the participants would then retrieve.

Following this hands-on demo exercise, participants could repeat the same tasks until they wished to stop. During and after their interaction with the Combadge, we interviewed them in the same group setting through interpreters on their technology baseline, experience using the Combadge, and other thoughts and suggestions about using voice messaging in their lives.

\section{Relevant Results}

Using the Combadge as a tool to ground our interactions, we were able to better understand existing communication patterns, familiarity with ICTs, and social dynamics and practices.

\section{A Buzz in the Community}

Sessions on the first day took place on the porch right outside a doctor's office. Though we initially wanted to conduct the study privately inside, our hosts convinced us that passers-by would feel more welcome to watch and even decide to participate if we stayed outside. There were a number of small shops that lined this street, and some shops were actually shop-houses in which the owners resided. The participants on the first day therefore lived or worked on that street.

For the next three days, our hosts invited (either by phone or in person) a number of their extended family members, friends and acquaintances to come to their home to participate in the study. Our hosts expressed that they felt obligated to call many of their relatives and friends lest they be accused of excluding them. Apart from the invited participants, there were a number of people who stopped by to see what was going on after hearing about the study from people that had previously participated.

The diversity of the participants was reflected by the social norms which they followed. Two young female participants of a lower caste than our hosts refused to sit on the furniture inside the house when we asked, because they considered it improper. On our last day, we moved our study from the inside of the house to the front yard because the invited field-workers belonged to the lowest caste in the community, and as such would not enter the house.

\section{Learning How to Use the Technology}

We observed several instances in which participants who had just used the Combadge showed new participants how to use it. Some participants learned to use the Combadge by observing others and asking questions to each other and therefore required no training. In some cases, spectators who were at first not interested in using the device eventually became less hesitant about making mistakes after seeing their peers struggle, and joined in.

Some observations suggested that we could effectively reach out to the uneducated populations through the educated by building on existing relationships between the two. All participants who were illiterate brought along an educated friend or child. Initially, they showed extreme reluctance to operate the Combadge. Only after explanations from their friends (and not just us) would they ease into participating more actively. For instance, a young uneducated woman refused to use the device, stating she did not know what to do, and handed it to her 8th-grade daughter. After observing us helping her daughter who was struggling with the device, she whispered instructions into her daughter's ear, thus demonstrating that she understood what to do but lacked confidence to use it herself. In another case, an older, uneducated man had difficulty operating the Combadge, so one of our hosts stepped in to help. He stated later that he preferred being taught by someone closer to his own status (like our host), rather than by young educated people like us. Finally, one young ninth grade boy was very confident that he would teach his illiterate parents how to use the device if he had one. Thus we saw conditions in which there could be willingness on the parts of both potential trainers and trainees.

\section{Projected Scenarios of Use}

A number of projected scenarios of use revealed the needs and current communication patterns of the local community. A carpenter said he could use the device to leave instructions for his employees when he went out, and they could send him messages when they ran into problems; currently all of their communication was face-to-face. This suggests the need for micro-entrepreneurs to efficiently coordinate work.

The local milkman said it would be convenient for him to use to inform customers when he was running late. Many such door-to-door services are conducted by providers traveling by foot or bicycle. Mobile, asynchronous communication devices could be particularly beneficial.

There were two scenarios which in a sense reinvented existing technologies: one woman said she might want to send a message to her daughter a few hours away at college which she could listen to when she came to her dorm. In this case the Combadge is playing the role of a stationary answering machine. In another case a man said it could be used to communicate between stories of a house, like an intercom. Thus, their scenarios were not restricted by the Combadge's functionality.

\section{Message Content}

Most participants were shy to send personalized messages in front of spectators, and so sent general inquiries about the receiver's health, or the rainy season. Some of them imagined that they were sending messages to people far away, such as children who were studying outside the village. However, when the field-workers who were at the 
lowest end of the educational and economic spectrum recorded their messages, they went on with messages aimed at their employers asking for higher wages, or recorded what appeared to be pleas for aid out of poverty, directed at anyone that could help. Listening to these messages provided us with an unexpected glimpse of their troubles.

\section{Relating to Existing Products and Services}

Many participants were informed about the technology market, even if they themselves were not regular consumers. One man said the Combadge should cost 50$60 \%$ of that of a cell phone because it had fewer functions, and another said around 2500 rupees/year (approximately US \$57). Participants asked about usage plans for the Combadge- would they buy pre-paid cards and be charged per message, or pay a monthly fee? The carpenter who wished to keep in contact with his employees asked for a "buy-one-get-one-free" deal since he saw that individual devices were not useful on their own.

In one discussion we received some self-reported statistics stating that in this particular area, $30-35 \%$ of the houses had land lines, and $15-20 \%$ owned cell phones. $40-60 \%$ of the homes had television sets, and this number was on the rise with the spread of cable. Out of the 64 participants, 33 made references to cell phones. Of these people, only 15 had ever used or owned a cell phone.

Finally, during one session, we found that there were a number of religious ceremonies for which people felt obligated to invite all of their acquaintances. For these frequent events, printing invitations and making house calls was not feasible, so people hired the "village messenger" to travel as far as 2 hours to make house calls. We found that issues with the village messenger were that he had to be paid for his travel, plus a salary, and he often could not be trusted to convey the message correctly. Through this discussion, the users revealed a clear need to improve on existing inefficient communication services.
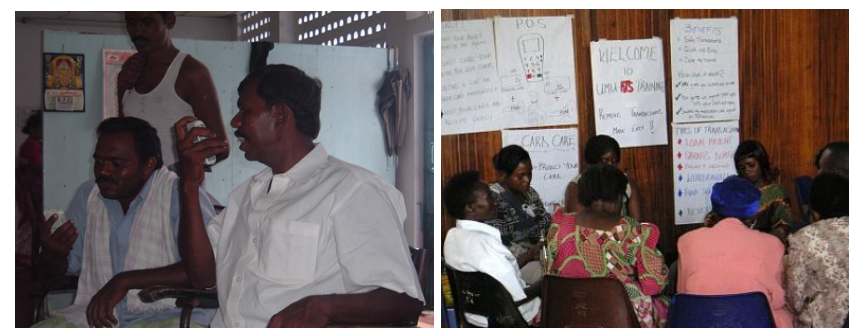

Figure 1a. Participants in TN using the Combadge. Figure $1 \mathrm{~b}$. Microfinance clients at a training session in Uganda.

FIELD STUDY \#2: MICROFINANCE IN UGANDA

Microfinance institutions (MFIs) provide financial services, e.g. savings accounts and small loans, to low-collateral individuals who are not traditionally serviced by mainstream financial institutions such as banks. Clients use these loans to start or operate small businesses, meet emergency needs, etc. Despite the perceived risks of lending to low-income borrowers, however, successful
MFIs such as the Grameen Bank in Bangladesh report repayment rates that are as high as $97 \%$ [10].

An MFI's reach is mostly limited to urban and peri-urban areas due to high transaction costs and operational inefficiency. MFIs are hence considering ICT solutions that enable them to service rural clients more cost-effectively. One possible solution, the Remote Transaction System (RTS) is a combination of technology and recommended business processes developed by the Microdevelopment Finance Team (MFT) based on market research. The MFT is a public-private sector consortium of microfinance leaders, technology specialists and business thinkers that Hewlett-Packard Company convened in August 2002. The RTS includes a point-of-sales (POS) device that can be taken into the field because it is portable and batterypowered. It is thus expected to be more cost-effective than alternatives such as operating an MFI branch office in a remote region.

A pilot deployment of the RTS was conducted in Uganda from January 2004 to March 2005 with three local partner MFIs. About $90 \%$ of Uganda's population lives in lowdensity rural areas, which reflects the above challenge of rural outreach to a major extent [3].

\section{System Description}

The POS device is an off-the-shelf Lipman Nurit 8000. It includes a smartcard reader, a printer for generating receipts, GSM cellular networking capabilities and customdeveloped software. Each individual client or group of clients uses a smartcard and personal identification number (PIN) to authorize transactions, which can be loan repayments, savings deposits, savings withdrawals, account transfers and balance lookups.

The first version of the custom software to be deployed in the pilot supported both online and offline transactions. Online transactions require real-time cellular connectivity that allows for instantaneous transmission of data from the device to a server that synchronizes incoming transactions with the systems at participating MFIs. On the other hand, offline transactions are "batched" on the device, to be uploaded when GSM cellular coverage becomes available.

\section{Methodology}

We participated as third-party evaluators in the RTS pilot for 3 weeks between August and September 2004. We observed two group meetings of clients from the same MFI who were using the POS device for their third time. Each meeting involved between 25 and 45 clients and a field officer, and was a biweekly event for group members to meet for 1-2 hours to perform microfinance transactions, e.g. loan repayments and savings deposits, regularly. During the meetings, we interviewed 5 clients from each group individually through an interpreter. Each interview lasted about 30 minutes and respondents were selected by the MFI's field officer to ensure variations in educational levels, comfort levels with technology and membership 
period in the group. The clients whom we interviewed had limited formal education and English literacy. Their ages ranged from 32 and 62, and most of them were women (most microfinance borrowers are women) [10].

We also observed the training sessions conducted by the pilot team to familiarize another MFI's clients and staff with the RTS solution and POS device. For the client sessions, 85 borrowers showed up. Each client's training lasted about 1.5 hours, and we observed 5 break-out groups comprising about 25 clients in total. The sessions that we chose to observe all took place in English, as this MFI's clients were better educated. For the staff training session, about 16 staff members attended. This session was conducted in English and lasted about 2 hours. The average MFI staff member, which includes the field officers, has a tertiary education. We also interviewed the management and staff members of the MFIs who did not participate in the above training sessions.

\section{Relevant Results}

Introducing the RTS and POS device to MFI clients and staff members provided a starting point for them to share important values and suggest how the combination of technology and business processes could be better designed to serve client needs.

\section{Learning How to Use the Technology}

Each client training session was restricted to 20 clients. It commenced with a facilitator from the pilot team explaining the benefits of the RTS to clients. He then provided an overview of the POS device and essential steps for using it. Next, clients were divided into small break-out groups of up to 7 members and each group was provided with a device. Each client was required to perform a loan repayment and a savings deposit transaction using the device before she was allowed to pass it on to the next person in the break-out group. Each session ended with clients from all break-out groups reconvening to discuss outstanding issues with the facilitator. The training session for staff members adopted the same format involving break-out groups, but involved a deeper coverage of the technical details.

For many clients, the first experience of learning to use the POS device appeared to be an intimidating experience. Many of them took notes during the briefing session. Many also struggled with the device and a few almost gave up. But with other break-out group members prompting and cheering them on, every client eventually succeeded in using the device to complete the above learning transactions herself. It appeared that encouragement from fellow clients helped to create a supportive learning environment within each break-out group. The clients' faces showed a sense of accomplishment and they remarked with pride and selfconfidence that the device was easier to use than they had originally expected.

Reactions of MFI Staff and Clients at Training Sessions Staff members and clients alike participated actively during the question-and-answer phase of their training sessions.
Clients from the MFI in question seemed excited about the RTS because it enabled microfinance services to be offered at the premises of a third-party agent, which was closer to their homes and workplaces. Without the RTS, clients had to visit the MFI's nearest branch office, which took as long as 4 hours round-trip via public transport.

But clients also attempted to identify limitations of the RTS. For example, clients pointed out the security risks of sharing their PINs and smartcards with other people, even though a staff member indicated that he did not encourage this practice. Upon further questioning, we learned that it was a common practice for clients to send proxies to perform loan repayments and other transactions on their behalf out of convenience. Unfortunately, clients would need to share their smartcards and PINs with their proxies. Some clients felt proud that they were supposed to keep their PINs a secret, even from their husbands: it gave them a feeling of independence.

Transparency about the agent fee was another concern. The first version of the RTS did not track the client's payment of such fees. As a result, it was more difficult for the MFI in question to regulate the fees that their agents might charge. A staff member preferred that the RTS have a feature to track this fee payment in its transactions.

Clients also asked about the policies that their MFI intended to adopt for the RTS. For instance, could a client make a larger loan repayment in one month and a smaller repayment in the next month? Would third-party agents be opened " 24 hours, 7 days per week" to make microfinance services more available? Could they make loan repayments on the device should they lose or forget to bring their smartcards? These questions suggested that clients could think of policies that could serve as starting points for envisioning scenarios of use associated with the RTS.

Similarly, staff members raised questions about airtime charges required to transmit transactions from the device to the RTS server. They wondered how much time it would take to send a transaction, and if airtime charges were calculated based on time or the number of characters transmitted. We learned later that airtime charges were part of a transaction's cost; clients would accept the RTS only if it was cheaper than transportation costs that they incur.

\section{Using the Technology at Group Meetings}

The clients who were using the RTS at group meetings for their third time were less educated and came from more rural backgrounds than the clients at the training. A field officer always attended meetings to check that accounts "added up" correctly. However, he often stepped in to perform paperwork for illiterate clients. As such, he was seen as an authority figure who represented the MFI. When clients had trouble with the RTS, they asked the field officer for help; when they observed him struggle with the device, they lost confidence in themselves to perform the transactions. 
Finally, although local cellular providers and infrastructure support companies had told the pilot team that $85 \%$ of Uganda had cellular coverage, we found that there was no coverage at both meeting locations. As such, the POS device had to be used in offline mode at both meetings. These field lessons prompted the MFT to develop a version of the RTS that was optimized for offline transactions.

\section{FIELD STUDY \#3: PRIMARY EDUCATION IN UTTAR PRADESH, INDIA}

As a part of an ongoing project we are conducting, we have been working with teachers and rural school children in Uttar Pradesh (UP), India to gain deeper insights about how computer and mobile technologies can be used to best meet the educational needs of students. The reader may refer to [12] for the detailed background and motivation for this project. We asked school children at our pilot school in Madantoosi, a village outside of Lucknow, UP, to use digital cameras to take pictures of their daily lives to help us better understand their values and local cultural practices, as well as give us an idea of how responsibly they could use mobile technology.

\section{Methodology}

Two low-cost digital cameras were utilized for the purpose of the project: a Concord 1200X and a DSC Pro. The participants consisted of 12 primary school children of ages ranging from 8-16 years old enrolled in classes on the upper spectrum of primary schooling. They were selected by our local NGO contact whom we had requested to select the children randomly based on basic computer skills. We loaned the cameras on a per-household basis, requesting siblings to share it. On each day over 2 weeks, both digital cameras were loaned to two different households, and the children were asked to take photos of their everyday lives to share with us.

On our first day in Madantoosi, we introduced all of the children to the general operation of the cameras and gave them an hour to take photographs and compile them into a collage. After this, prior to each child's turn to take the camera home, he/she was personally trained on the camera and tested to ensure that he/she understood its operation completely. On the following day, the child was given the chance to share the photographs with an interviewer, interpreter and observer. The photographs facilitated the interviews, and were used to ask detailed questions about the people and practices pictured.

We found that the children could be trusted to be responsible for the digital cameras. They returned the cameras undamaged and on time everyday. On a particular rainy day, the children took precautions to avoid wetting the cameras by wrapping them safely in their clothes.

When we loaned out the cameras, we specifically requested the children to photograph subjects which they valued and which were important to their lives outside of the school setting. The photographs can be categorized into groups of
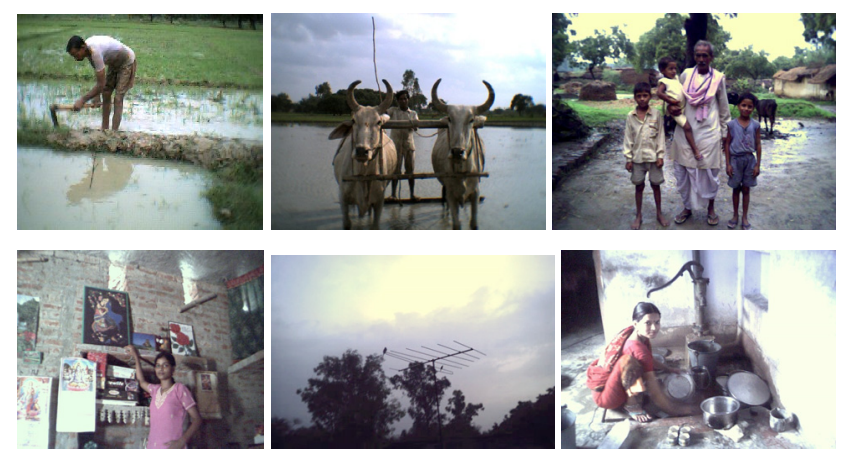

Figure 2. Photos taken by UP participants.

family, community and private property, suggesting the significant importance of these domains in their lives (for examples, see Figure 2).

\section{Family}

Family appeared to play an important role in the lives of the children. $23 \%$ of all the photographs collected showed images of relatives. Through the interviews, we found that most of the children lived in very close proximity -if not next door- to their relatives, and therefore interacted with them frequently. The children's definition of "family" incorporated not only their immediate family but also their extended family members.

\section{Community}

Whereas school served as a place for the children to convene and socialize daily, in general the villagers all congregated at the temple and its surrounding areas. Many photographs showed that visiting the temple for communal and religious activities was a daily routine for most of the children. Aside from photographs of their relatives, teachers and friends, participants would take opportunistic shots of their fellow village residents. There were random shots of passers-by, including the school gardener, village washerman and tractor driver. There were also incidents when passers-by (in one case the son of the village chief) asked to be photographed.

One particular child at the school who was not a participant wanted to borrow the camera for a night to take pictures as well. At times, the child to whom the camera was loaned would appear in the photos as well. 7 out of the 12 children shared the cameras with their family and friends. Thus, the children trained new photographers on how to operate the camera, and reported that training was not a difficult task.

\section{Private Property/Socioeconomic status}

The children also photographed their families' private property, such as household furniture (e.g. tables and benches), motorcycles, bicycles, livestock (e.g. oxen, buffaloes, cows, goats and dogs) and fields. Through the items photographed, we could place the children in relative socio-economic backgrounds. One child's family owned a machine that ground wheat into flour. This child informed us that while other people in the village owned similar machines, there were none near her house. When we came across a photograph of a TV antenna, we learned that only 
5-6 households in the village owned television sets. Some houses had indoor plumbing, while others did not as demonstrated by a photo of a relative taking a bath in the courtyard. Some students had access to expensive equipment like cell phones, televisions, motorcycles and bicycles, although they did not own it themselves. From a photo showing a relative using a cell phone, we learned that half of the village had access to a cell phone.

\section{Limitations}

Limitations regarding the use of digital cameras were identified after their return. These could be categorized into three types: limitations of knowledge, usability and memory.

Some of the children returned the cameras with their AAA batteries removed because they had taken them out and did not know how to insert them back in correctly.

$45 \%$ of the photos resulted in error shots, which included the photo subjects with their heads cut off, black/near-black photos, blurry shots and stray shots that the photographers did not intend to take. $12.5 \%$ of these photos were recognizable even though they were blurred. $7 \%$ of the photos were stray shots. $15 \%$ of the photos were unrecognizable. The high volume of error shots indicates that the photographers were not entirely proficient with the digital cameras.

Children quickly realized that there was a memory limitation to the cameras. On average, the photographers took more pictures with the DSC Pro camera since it had a larger memory. $83 \%$ of the photographers took pictures until the memory was full. Therefore, we presume that they might have wished to share more had they not been limited by memory.

\section{DISCUSSION}

The previous sections relate relevant results from three separate field studies. However, this section is a result of many conversations in which we reflected on and compared our experiences from the studies to find some surprising underlying similarities. The binding force is the use of technology artifacts as aids for gathering information. In addition, we compare and contrast how the environment in which the studies were conducted contributed to the types of information we obtained. Two qualities mark all the participants: (1) low exposure to technology, and (2) strong sense of community. We and our colleagues have seen both these qualities as characteristic of people in the greater developing regions realm, and so we generalize our lessons as applicable for engaging local stakeholders in developing regions in the early stages of co-design.

\section{Technology Artifacts}

The following two subsections highlight how the presence of technology artifacts is important for understanding local attitudes toward technology and inspiring design ideas from populations with limited exposure to technology.
Lesson \#1: Use the artifacts to assess the technology baseline and market expectations of the community.

The technology baseline of users in developing regions can often be a surprise. Interventions such as local government policies, NGO initiatives, or cable and mobile phone coverage control technology exposure in different regions. The use of technology artifacts during our interviews provoked discussion about previous exposure, i.e., comparisons to cell phones in $\mathrm{TN}$, and photographs in UP of technologies in the home and fields. In TN and Uganda, more educated local stakeholders served as expert informants, turning our attention towards issues of pricing, liquidity and income sources that we otherwise may not have considered. As such, artifacts appear to be useful tools in provoking stakeholders to share thoughts about issues affecting the commercial sustainability of technology solutions in low-income markets, which is an adoption challenge cited by Prahalad [21].

Lesson \#2: Design tasks for participants to perform using the artifacts in order to elicit response.

In all three cases, we observed participants' use of technology artifacts which completely supported at least a few tasks, even if two were still semi-functional prototypes. However, regardless of the completeness of the artifact, we found that the task assigned to the participant more directly dictated the types of results we obtained. With the POS device, the user was asked to perform two clear-cut transactions specific to microfinance management. As such, the feedback was much like what might be gathered in usability testing (i.e. transparency of the agent fee), where not much other cultural information was revealed.

However, in the cases of the Combadge and the digital cameras, the tasks were more open-ended, allowing a personal touch. Participants in TN could send any kind of message to the recipient, and the school children took pictures of whatever they liked. Thus, as the TN participants contemplated the content of the message, they could envision a broad range of scenarios of use, revealing information like common door-to-door services. The messages recorded by the field workers opened our eyes to how deeply affected they were by poverty. Furthermore, some users extrapolated on Combadge features through projected scenarios to literally reinvent existing technologies which they had never seen, like the stationary answering machine. Similarly, the photographs presented a much broader snapshot of daily life extending well beyond the application domain. Though the cultural practices pictured were not linked to scenarios of technology use directly, we were able to later use the data to understand what times and spaces in their lives afforded technology use. Thus, we see that regardless of their limited exposure to technology, participants can provide feedback valuable to design by performing tasks using artifacts; open-ended tasks can reveal a broader perspective of their lives. 


\section{Inside the Community}

We reiterate that it is essential for researchers in developing regions to have the help of a local guide [16], but extend this to say that they should also attempt to immerse themselves within the community. The following three sections explain how the environment in which technology artifacts are used can help researchers uncover valuable socio-cultural information through observations of users situated within the context of the greater community.

Lesson \#3: Open up the study as a community event in order to attract participants from widespread backgrounds.

The mere fact that we brought along new foreign technology was enough to draw attention within the community. Whereas in Uganda, the participants were all pre-selected microfinance clients, in TN and UP, talk of the technology spread throughout the community. In $\mathrm{TN}$, as per the suggestion of local informants, sessions were held in open welcoming spaces, and invitations were sent to everyone. As a result, participants in TN who had positive experiences with the Combadge brought their relatives, friends, etc. Others came because they had heard of the study and were curious. Unlike traditional snowball sampling wherein respondents recommend who the researcher should interview next, the Combadge made community members excited enough that they undertook the responsibility of recruiting subjects voluntarily on behalf of the researcher. Similarly, in UP, a student at the school requested to borrow a camera for a night. Since the cameras were loaned out for use directly by children of the community, some individuals appeared in the UP photographs because they had met the children while they were taking photographs (i.e. opportunistic sampling). Thus, we believe that the draw of technology itself can help recruit participants representing varying backgrounds.

However, it is more important that the environment in which the technology is presented should be in line with local expectations - likely open and welcoming in tight-knit developing regions communities. Because we let our local guide in TN suggest how we conducted the sessions, our process did not appear foreign to the community, and thus they felt comfortable participating and bringing others. Similarly, we gave total ownership of the camera to the children in UP, and thus they were able to share it with others. We recognize that such sampling procedures may introduce selection biases, such as attracting respondents who are interested in technology, but argue that these procedures could be combined with other procedures such as random selections and screening. Finally, we are aware that this process may not be applicable when targeting highly specific communities, such as in the Uganda study.

Lesson \#4: Allow peers to help one another to encourage participation and observe learning dynamics.

Building on the closeness of the community mentioned above, we found that peer learning was a natural part of local practices. In TN and Uganda, working in small groups tended to have an empowering effect on participants, especially if they were lacking confidence. We observed group members offering encouragement and advice to each other. Less educated participants said that they preferred to receive explanations on how to use the Combadge from their friends or peers of the same educational level, as opposed to us. The most illiterate people in TN depended on their children to make sense of the Combadge, and some were only willing to try after observing their peers. In both Uganda and $\mathrm{TN}$, group members would engage in discussions on how they could use the device. Similarly in UP, we saw that 7 out of 12 school children felt confident enough to teach their friends or family to take pictures. The demonstrated willingness to learn, teach and share could have implications for effective deployment of new technologies within a community. The open nature in which we allowed participants to interact with the technology artifacts allowed us to observe social dynamics of learning among peers, as well as encouraged more users to participate.

Lesson \#5: Create opportunities to observe social dynamics at different levels within the community.

Apart from the peer learning dynamics, we also observed other interesting relationships at both the personal and class levels. Interviewing the children in UP about the individuals in the photographs helped us understand who they interacted with regularly, and how they were related, e.g. parent-child, teacher-student, sibling, neighbor, buddy, etc. relationships. In $\mathrm{TN}$, the manner in which the Combadge drew respondents together to interact with the device revealed a lot of the social norms they followed, the most novel being those between people of different castes, and between illiterate and literate friends and family. In Uganda, visits to fortnightly meetings helped us observe the dynamics between the clients and officer. Had we visited homogenous groups individually, or conducted only private interviews, we would have missed this important aspect of their lives. Given the prevalence of community ties and strict social strata in developing regions, we expect that by employing technology artifacts in social settings, we can observe social networks that reveal how community members are related, as well as observe how these social relations affect and are affected by their interaction with and acceptance of technology. This knowledge can, for instance, enable designers to identify stakeholder relations which are critical to the adoption of technologies with strong network effects and design accordingly for them.

\section{CONCLUSION}

Based on our experiences, we demonstrate that it is possible to engage local stakeholders in developing regions for early stage co-design. Introducing technology artifacts to users with limited exposure appears to be effective for attracting participants and assessing their expectations. Observing participants in their community settings reveals social relationships highly relevant to successful deployment. Researchers can use the cultural information they gather as starting points for the design and deployment of new 
technologies that better fit local needs and practices in developing regions.

A topic of recent debate has been the importance of drawing broad design implications from ethnographic research [5]. We relate three narratives in great detail to capture the high degree of context from which we draw our lessons. We identify common characteristics of these communities that suggest that we could also engage local stakeholders in other similarly tight-knit communities, perhaps even those found in the developed world. The diversity between the three narratives, specifically in the cultural norms and practices of these relatively unexplored communities, cautions us in pursuing broader design guidelines. Alternatively, we see the rich narratives of our work and experiences in the relatively new, developing regions context as a stand-alone contribution - providing a fresh perspective on early-stage design to the greater $\mathrm{CHI}$ audience.

\section{ACKNOWLEDGMENTS}

For the Tamil Nadu study, we thank Udhyakumar Nallasamy and Srinivasan Ramaswamy, as well as Mitsubishi Electric Research Labs. For the Uganda fieldwork, we thank Tu Tran, the Microdevelopment Finance Team and the local pilot team for their enormous support. In particular, we thank Janine Firpo and Laura Frederick for their guidance and feedback. This study was supported by a fellowship program between the United Nations and UC Berkeley's Management of Technology Program, while the pilot was supported by the United States Agency for International Development (USAID). For the Uttar Pradesh field study, we thank Urvashi Sahni for hosting our visit and Anand Raghavan. This study is funded mainly by the National Science Foundation (USA) under EIA-0326582. We thank Paul Aoki, our colleagues at the Berkeley Institute of Design and our anonymous reviewers for their feedback, and of course, our participants.

\section{REFERENCES}

1. Beyer, H., and Holtzblatt, K. Contextual Design: A CustomerCentered Approach to Systems Designs. Morgan Kaufmann, 1997.

2. Brewer, E., Demmer, M., Du, B., Ho, M., Kam, M., Nedevschi, S., Pal, J., Patra, R., Surana, S., and Fall, K. The Case for Technology in Developing Regions. IEEE Computer, 38 (6), June 2005, 25-38.

3. Central Intelligence Agency. The World Factbook 2003. URL: http://www.cia.gov/cia/publications/ factbook/geos/ug.html (last accessed: March 8, 2004).

4. Chen, S., and Ravallion, M. How Have the World's Poorest Fared Since the Early 1980s? World Bank Policy Research Working Paper 3341, June 2004.

5. Dourish, P. Implications for Design. In Proc. CHI 2006, ACM Press (2006), 541-549.

6. Frankel, J.L. and Bromberg, D. Combadge: A voice messaging device for the masses. Third International Conference on Innovative Applications of Information Technology for the Developing World (Asian Applied Computing Conference), 2005.

7. Gaver, B., Dunne, T. and Pacenti, E. Design: Cultural Probes. Interactions 6, 2 (1999), 21-29.
8. Gaver, W. and Dunne, A. Projected realities: Conceptual design for cultural effect. In Proc. CHI 1999, ACM Press(1999), 600-607.

9. Get it Started: Wharton Entrepreneurial Programs. He's GotConnections.

URL:http://www.wep.wharton.upenn.e6u/newsletter/fall04/co nnections.html (last accessed: September 22, 2006).

10. Grameen Bank. Breaking the Vicious Cycle of Poverty Through Microcredit. URL: http://www.grameeninfo.org/bank/bcycle.html (last accessed: September 22, 2006).

11. Hutchinson, H., Hansen, H., Roussel, N., Eiderback, B., Mackay, W., Westerlund, B., Bederson, B., Druin, A., Plaisant, C., Beaudouin-Lafon, M., Conversy, S. and Evans, H. Technology Probes: Inspiring design for and with families. In Proc. CHI 2003, ACM Press (2003), 17-24.

12. Kam, M., Ramachandran, D., Sahni, U. and Canny, J. Designing Educational Technology for Developing Regions: Some Preliminary Hypotheses. In Proc. of IEEE $3 \mathrm{rd}$ International Workshop on Technology for Education in Developing Countries, 2005.

13. Kam, M., Ramachandran, D., Raghavan, A., Chiu, J., Sahni, U., and Canny, J. Practical Considerations for Participatory Design with Rural School Children in Underdeveloped Regions: Early Reflections from the Field. In Proc. Interaction Design and Children 2006, ACM Press, NY, USA

14. Maddison, A. The World Economy: A Millennial Perspective. OECD, Paris, France, 2001.

15. Medhi, I., Sagar, A., Toyama, K. Multiple Mice for Computers in Education in Developing Countries. In Proc. of 2006 International Conference on Information and Communication Technologies and Development.

16. Millen, D. Rapid Ethnography: Time deepening strategies for HCI field research. In Proc. DIS 2000, ACM Press (2000), 280-286.

17. Parikh, T.S., Ghosh, K., Chavan, A., Sayal, P., and Arora, S. Design studies for a financial management system for microcredit groups in rural India. ACM Conference on Universal Usability, 2003.

18. Parikh, T.S, Javid, P., Sasikumar, K., Ghosh, K., Toyama, K. Mobile phones and paper documents; evaluating a new approach for capturing microfinance data in rural India. In Proc. CHI 2006, ACM Press (2006), 551-560.

19. Pawar, U., Pal, J., Toyama, K. Text-Free User Interaces for Illiterate and Seim-Literate Users. In Proc. of 2006 International Conference on Information and Communication Technologies and Development.

20. Plauche, M., Wooters, C., Ramachandran, D., Pal, J., Nallasamy, U. Speech Recognition for Illiterate Access to Information and Technology. In Proc. of 2006 International Conference on Information and Communication Technologies and Development.

21. Prahalad, C.K. The Fortune at the Bottom of the Pyramid: Eradicating Poverty through Profits. Wharton School Publishing, Upper Saddle River, NJ, USA, 2004.

22. Rodgers, E.M. Diffusion of Innovations. The Free Press, New York, NY, 1995.

23. Sachs, J. The End of Poverty: Economic Possibilities for Our Time. The Penguin Press, NY, USA, 2005. 